\title{
ScIDide
}

\author{
International Journal of Dentistry and Oral Science (IJDOS) \\ ISSN: 2377-8075
}

\section{Sensory Neuropathy Type V: Dilemma Between Function and Well-being}

Meriam $\mathrm{BB}^{1^{*}}$, Manel $\mathrm{C}^{1}$, Jihène $\mathrm{Z}^{2}$, Malèke $\mathrm{D}^{1}$, Imène $\mathrm{G}^{3}$, Jemmali $\mathrm{B}^{3}$

${ }^{1}$ Resident in Pediatric Dentistry, La Rabta Hospital, Tunisia.

${ }^{2}$ Assistant in pediatric Dentistry, La Rabta Hospital, Tunisia.

${ }^{3}$ Professor in pediatric dentistry, La Rabta Hospital, Tunisia.

Abstract

Introduction: Hereditary sensory and autonomic neuropathies type V (HSAN type V) is the rarest of sensory neuropathies. The main features are loss of deep sensitivity as well as self-mutilation of especially the lips, fingers, tongue and teeth. Case Report: In this article we report a rare case of a 4-year-old child with HSAN type V. the patient's management had two aims first reinforce parental and child compliance and then restore function and aesthetic.

Discussion: The diagnosis of a HSAN type V relies not only on the clinical features but also on the genetic analysis. Dental management and careful monitoring are key elements in maintaining social, psychological and behavioral equilibrium of these patients.

Keywords: Congenital Insensitivity to Pain; Hereditary Sensory and Autonomic Neuropathy; Self-Mutilation; Dental Management.

\section{Introduction}

Hereditary sensory and autonomic neuropathies (HSAN) are autosomal recessive disorders characterized by the loss of deep pain perception [1]. Six types of sensory neuropathies are reported in the literature [2], with different prevalence and clinical features. The rarest one is HSAN type $\mathrm{V}$ and it manifests from early childhood. An epidemiological study conducted in Japan reports a prevalence of 1/2,200,000-4,200,000 [3], but epidemiological data are still missing.

Patients with HSAN type $V$, have an altered pain protection reflex associated with a significant reduction in the number of amyelinated fibers. This insensitivity to pain increases the risk of fracture and injury that usually go unnoticed until complications develop. The tactile, vibratory and thermal sensations are not impaired. Unlike HSAN type IV, type $\mathrm{V}$ has intact mental abilities and partial anhidrosis. In addition, self-mutilation is an invariable characteristic of the disease, and it often involves lips, fingers, tongue and teeth $[1,4-8]$.
This clinical observation exposes a rare case of hereditary sensory and autonomic neuropathy type $\mathrm{V}$ in Tunisia (North Africa), and stresses the importance of the involvement of the pedodontist in the management of the complications of this pathology.

\section{Case Report}

A 4-year-old child was referred from the Tunisian National Institute of Neurology to the Pediatric Odontology Consultation Service at the Rabta University hospital-Tunis-Tunisia for early loss of temporary teeth. It was mentioned in the physician's letter that the patient was suffering from a sensitive neuropathy type $\mathrm{V}$. A thorough clinical interview with the parents showed that the patient was born from a first-degree consanguineous marriage, that pregnancy and delivery were normal, without any special incidents. The child's mental capacities were intact and she integrated well with the children of the maternal school. Her parents began to progressively discover their daughter's insensitivity to pain since the age of 6 months. Indeed, when the first teeth began to erupt, the patient bit her tongue and her fingers (Figure 1).

\section{*Corresponding Author:}

Ben Brahim Meriam,

Resident in Pediatric Dentistry, La Rabta Hospital, 8 street Mohamed Ibn Rabeh Gorjeni 2072 Tunis, Tunisia.

Tel: 0021695822628

E-mail: meriambenbrahim@gmail.com

Received: August 29, 2017

Accepted: September 25, 2017

Published: September 26, 2017

Citation: Meriam BB, Manel C, Jihène Z, Malèke D, Imène G, et al., Sensory Neuropathy type V: Dilemma Between Function and Well-being. Int J Dentistry Oral Sci. 2017;4(9):528531. doi: http://dx.doi.org/10.19070/2377-8075-17000104

Copyright: Meriam BB $\mathbf{B B}^{\circ}$ 2017. This is an open-access article distributed under the terms of the Creative Commons Attribution License, which permits unrestricted use, distribution and reproduction in any medium, provided the original author and source are credited. 
Clinical examination showed an ulcerated and extensive perioral lesion. According to dermatologists, it was a self-sustained cutaneous lesion (Figuer 2). Endobuccal examination showed the absence of the four maxillary incisors (Figure 3a) and the mandibular incisivo-canin group (Figure 3b). Parents ignored the cause of this premature loss of temporary teeth. However, they confirmed the self-amputation of the anterior extremity of the tongue since the age of 6 months (Figure 4). Temporary molars were also decayed.

In fact, the risk of self-mutilation of the lips and tongue by the anterior teeth has become low due to the early loss of this teeth. However, the masticatory and phonatory functions were altered, which will also lead to the installation of parafunctions.

After a long reflection and evaluation of the benefit/risk balance, we have decided to realize $\mathrm{T}$ two fixed space maintainers (Figure
$5 a, 5 b, 5 c)$ and we tried to explain to the parents the importance of their involvement in the treatment and the rigorous follow-up of their daughter at home.

The psychological approach of the patient and the parental supervision were of great importance in the success of a large part of our treatment plan. Indeed, the appointments of control were so close. Thus, during the first 3 months, we did not witness a return to self-mutilation, but rather to repetitive loss of space maintainers. We removed the prostheses, and the follow-up was always regular. After one year, the patient no longer self-mutilates, however, the 4 mandibular permanent incisors and the two maxillary ones have already made their premature eruptions with crossbite occlusion. (Figure 6a and 6b). A functional educator will be recommended in order to restore a normal bite without exerting excessive forces on the incisors still root-free.

Figure 1. Self-mutilation of the fingers.

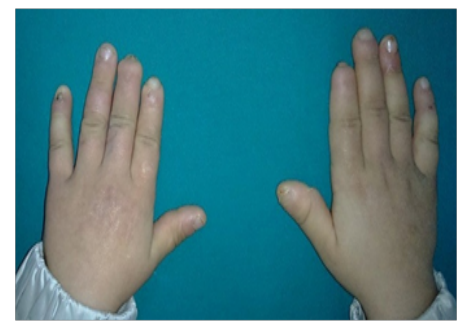

Figure 2. Self-sustained cutaneous lesion.

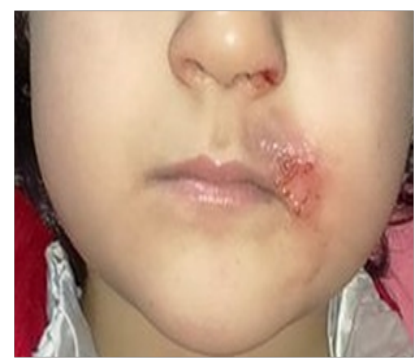

Figure 3a. Absence of maxillary incisors.

Figure 3b. Absence of the mandibular incisivo-canin group.
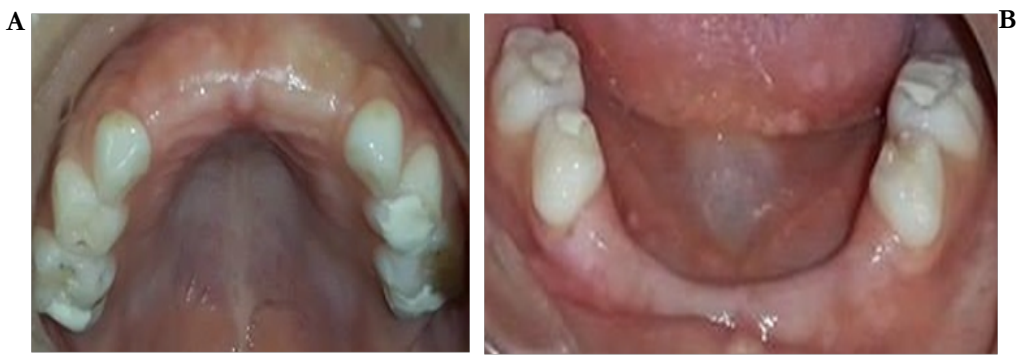

Figure 4. Self-amputation of anterior extremity of the tongue.

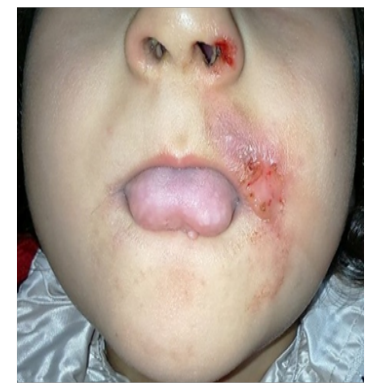


Figure 5a. Maxillary fixed space maintainer.

Figure 5b. Mandibular space maintainer.

Figure 5c. Prosthetic rehabilitation.
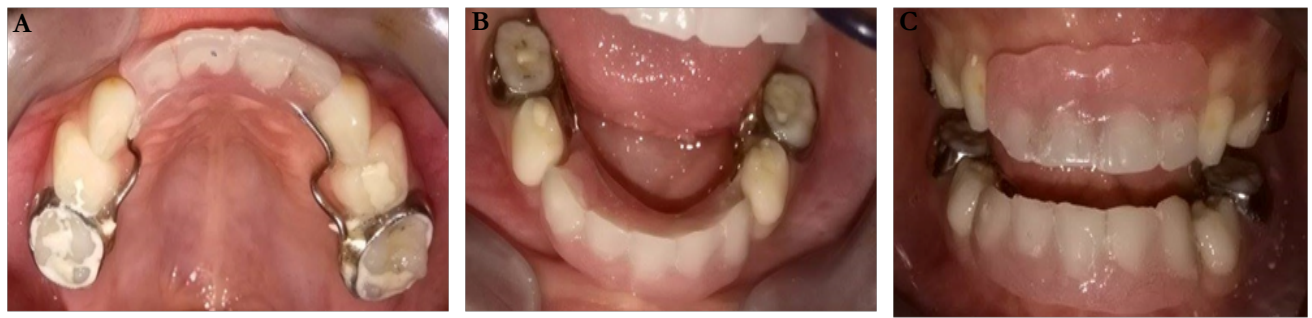

Figure 6a. Panoramic radiography : Root-free incisor's eruption.

Figure 6b. Anterior cross-bite.
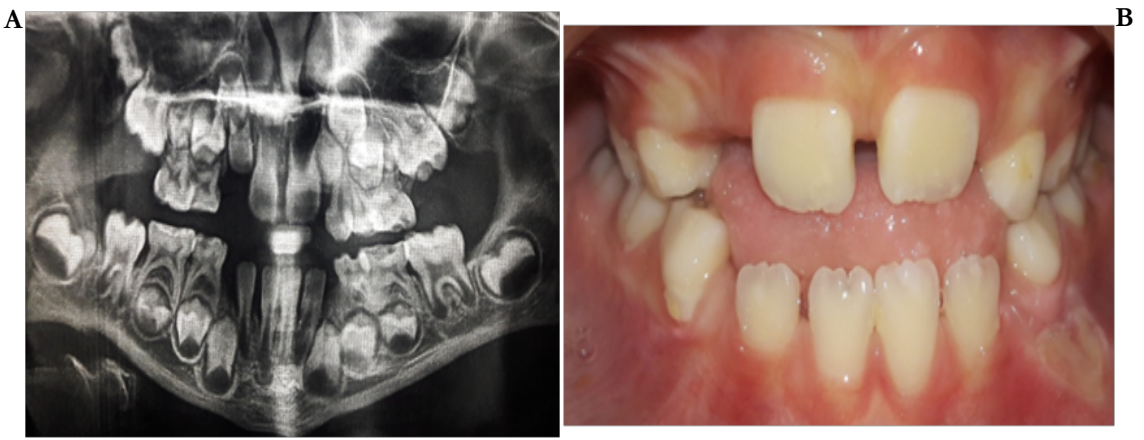

\section{Discussion}

Hereditary sensory and autonomic neuropathy (HSAN) is an extremely rare autosomal recessive pathology first described in 1978 in a 6-year-old Lithuanian girl [4].

This anomaly affects in a remarkable way the sensitivity to pain and consequently the protection's reflexes. Our patient presents insensitivity to pain, absence of mental retardation and notably self-mutilation of her fingers, lips and tongue. All this clinical manifestations are reported in the literature and found in the rare published cases [1, 4-8]. EMG exploration was in favor of sensitive neuropathy. As for the biopsy, the muscle was normal. Currently, the genetic examination is under way (In France).

In these patients, the different pathologies progress silently until complications appear [4]. For oral diseases, there is often a silent development of the carious lesions until the establishment of complications such as abscess and cellulitis. Hence the importance of oral prevention in these patients who, fortunately, are not mentally retarded and can be involved in the treatment plan. For our patient, a session was devoted for motivation to hygiene and teaching a good method of teeth brushing. Caries were also treated.

Till today, there is no effective treatment for this neuropathy. Patient management is essentially based on vitamin therapy, Protection from hypothecy and self-mutilation through the use of socks and protective gloves and, finally, the prevention of injuries and the prompt treatment of wounds and infections.

For self-mutilation and self-extraction, the differential diagnosis of HSAN type V is with Lesh Nyhan syndrome and Cornelia de Lange syndrome. However, this syndroms involve mental retardation, which may influence the treatment decision and the course of the care sessions. In the literature, treatment options balance between the multiple extractions of all teeth and the confection of a thermoformed gutter for protection against self-extraction and self-mutilation [6-8].

In the case of our patient, social integration looks promising despite her young age, and in view of the fact that multiple extractions is traumatic for the child, we chose not to disturb her psychology. Furthermore, the use of the thermoformed gutter seems unnecessary since the patient has already lost all the anterior teeth. Moreover, the prosthetic rehabilitation finds all its indication. On the one hand, it will help to stimulate the alveolar bone consequently the root edification of permanent incisors still immature but close to the summit of the crest. On the other hand, the patient will quickly find both one's correct functions and beautiful smile.

The failure of the prosthetic solution is essentially due to the mandibular proglissement that took place due to the absence of the incisors groups. Continuous control, by the pedodontist and parents, is necessary to intercept any infectious and/or dentoalveolar abnormalities.

\section{Conclusion}

Sensitive neuropathy type $\mathrm{V}$ is an extremely dangerous anomaly. Its diagnosis and management are of a major challenge, especially for the pedodontist. This dilemma between function and wellbeing requires careful study of the benefit/risk balance in order to establish the best treatment plan.

Dental management and careful monitoring are key elements in maintaining the patient's social, behavioral and psychological equilibrium, at least in early childhood. 


\section{References}

[1]. de Andrade DC, Baudic S, Attal N, Rodrigues CL, Caramelli P, Lino AM et al. Beyond neuropathy in hereditary sensory and autonomic neuropathy type V: cognitive evaluation. Eur Js Neurol. 2008 Jul;15(7):712-719. PubMed PMID: 18498365.

[2]. Edvardson S, Cinnamon Y, Jalas C, Shaag A, Maayan C, Axelrod FB, et al. Hereditary Sensory Autonomic Neuropathy Caused by a Mutation in Dystonin. Ann Neurol. 2012;71(4):569-572. PubMed PMID: 22522446.

[3]. N Haqa, Kubota M, Miwa Z. Epidemiology of hereditary sensory and autonomic neuropathy type IV and V in Japan. Am J Med Genet. 2013 Apr;161A(4):871-874. PubMed PMID: 23495212.

[4]. Capsoni S. From genes to pain: nerve growth factor and hereditary sensory and autonomic neuropathy type V. Eur J Neurosci. 2014 Feb;39(3):392400. PubMed PMID: 24494679.

[5]. Houlden H, Blake J, Reilly MM. Hereditary sensory neuropathies. Curr Opin Neurol. 2004 Oct;17(5):569-577. PubMed PMID: 15367861.

[6]. Kalaskar R, Kalaskar A. Hereditary sensory and autonomic neuropathy type V: Report of a rare case. Contemp Clin Dent. 2015 Mar;6(1):103-106. PubMed Central PMCID: PMC4319325.

[7]. Singla S, Marwah N, Dutta S. Congenital Insensitivity to Pain (Hereditary Sensory and Autonomic Neuropathy Type V): A Rare Case Report. J Dent Child. 2008 Aug;75(2):207-21. PubMed PMID: 18647521.

[8]. Romero M, Simón R, Garcia-Recuero JI, Romance A. Dental management of oral self-mutilation in neurological patients: A case of congenital insensitivity to pain with anhidrosis. Med Oral Patol Oral Cir Bucal. 2008 Oct;13(10):644-647. PubMed PMID: 18830173. 